\title{
Digital media learning in the third space.
}

In this article we share the outcomes of two fieldwork focus groups conducted for triangulation as part of a larger project investigating 'third space literacies' (Potter and McDougall, 2017) in digital media learning contexts. One focus group brought together an international group of media education practitioners at the Media Education Summit in Rome. The other was a transcribed conversation between four published researchers in the field, ourselves, Neil Selwyn (2014) and Cathy Burnett (see Burnett et al, 2014). The data from these two fieldwork activities was first presented as an afterword to our book 'Digital Media, Culture and Education: Theorising Third Space Literacies' (Palgrave MacMillan, 2017).

Here, we present the outcomes and discuss their implications for the themes addressed in this special issue, namely contemporary forms of participation in formal and informal learning. Our contribution is a theoretical and research informed position, drawn from Cultural Studies, new literacy studies and educational research, on the 'conditions of possibility' for learning to take place in the 'third space' across and between these domains. This space facilitates dynamic literacies, curational practices and a porous exchange of knowledge. Purposive use of such a space can answer questions about the use of digital media for teaching and learning in school, the affordances of transmedia for education and the connection of teaching and learning in and out of school.

Our research into third space literacies (Potter and McDougall, 2017) led to three significant findings for the frame of reference for this issue.

(1) Dynamic literacies - this way of thinking about literacies as agentive, social and situated practices rather than individual competences takes us beyond media literacy as an extra / other to literacy and offers a sharp contrast with the static nature of the literacy of performative systems, being inclusive of various other liminal, spatial and technological literacies and concerned with the sociomateriality of digital media. Researching dynamic literacies means employing dynamic methodologies which draw on focused ethnography, multimodality, and which engage social actors as researchers of their lived experience

(2) Third Spaces - when digital media is used to create a third space (between school and home / community) with the effect of transgressing disciplines and traditional ideas about knowledge and expertise, educational practices can'shape-shift' to challenge epistemological power relations.

(3) Digital media curation is a new form of cultural production and literacy practice. Understanding the skills, knowledge and dispositions which go with it as a practice and building on them in education is an urgent objective if we are to make meaningful connections between teaching and learning in and out of school.

Following our major data analysis, we conducted two forms of triangulation, which we offer here. Firstly, we designed a focus group to seek the insights and provocations of two formative 'agents' in our fields of enquiry, Cathy Burnett and Neil Selwyn. Secondly, we recorded, as participant observers, a workshop on these three key findings at the Media Education Summit in Rome, with an international group of media education and media literacy practitioners. This triangulation stage serves as a third space in itself, neither part of the research described in the book itself, nor an 'external' review and neither a live symposium on the themes nor a retrospective account of them. We offer this as a credible and reflexive working out / working through of our findings with both experts in the field we are working in and the community of practice we want to talk to, including the readership of this journal. 


\section{Triangulation 1: conversation with field agents:}

Julian - looking back at our findings, third space is a big idea but we, inevitably I suppose, speak to that concept in multiple ways. If we need to pin it down, what are we talking about when we talk about third spaces?

John - We're talking about negotiated spaces, where meanings are made and shared. In an educational context that's any space in which attention is paid to the habitus, or learned and practised way of being, of the other party in any communicative act, which is why we've often spoken about it in the context of porous expertise. But Bhabha (1994) implied it was a space through which all utterances needed to pass before meaning inheres between the social actors in that space. So it's important to think of it in that way because it is not, therefore, an actual physical location; it is not necessarily an after school club or a museum education space or an art studio. That way of being around learning and knowledge is associated with those spaces which are neither home nor school because of the effect on the negotiated meanings in those spaces, the ways in which hierarchies are changed. The signature pedagogies in those after school clubs and spaces are qualitatively different because they exist in a third space which demands that the values and the culture of the participants feature in the space. But they can be created maybe in school as much as out of school. So what we are talking about - I suppose - is negotiated space. Third spaces are contested, negotiated and political.

Julian - you finished with 'political' and in a way that reminds me of Prensky's distinction between nouns and verbs during that very problematic 'Media 2.0' debate (see Berger and McDougall, 2011). Whilst his 'digital natives' is something we've moved (far) away from, his distinguishing between the technology (nouns) and the human ways of working it enables (verbs) was far more helpful during that period when media educators were oscillating wildly around a before and after, either / or discourse about new media and the internet. With third spaces, it's the same idea, at the most reductive level a third space can just be a thing, a place in between two other things, but in the political sense it's a verb, an active site of powerful negotiation of being a person in education, and I think we've drawn that line pretty clearly. We've written about those third spaces which look like they are making a difference to the second space, often by taking back to that space a different way of thinking about knowledge and also those that seem just to extend it - e.g. several of the 'not school' cases. So the kinds of political third space education we see as enabling rich, powerful digital media literacies work is that which really offers a space for resistance to power, at its most simple, in media education it is the difference between observing power and 'fight the power' - the difference between a question such as How might we need to think the traditional categories of learning: reading and writing, speaking and listening? and something like How have these categories previously stopped people having a voice, how will YOU thinking differently about literacy to include digital media lead to a redistribution of cultural capital?

Neil - Language is clearly important here ... in particular the terms used to convey the essence of these issues and ideas to broader educational audiences. So, I'm left wondering whether it might be reasonable to conclude a research project about 'theorising third space literacy' with the suggestion that we need to think of more direct ways of conveying our concerns with politics, power/resistance, exclusion and so on? So what would you be calling these practices/sites if you hadn't read Bhabha? How might we more crudely (but perhaps more successfully) rebrand 'Third Spaces' in a way that conveys everything that you've just outlined - i.e. that these are sites of ongoing political struggle and negotiation. I am often struck by how the field of education can take quite powerful and politically-astute concepts and neutralise them to the point of banality. Think of how an initially powerful concept such as 'Communities of Practice' now gets bandied around in the most banal terms of 'people doing stuff together in groups. Or 'Affordances' gets reduced to 'things that you can do with 
something'. Or the ways in which Activity Theory is used in many educational contexts. Given these precedents, I am worried that the important ways in which you are outlining Third Spaces might get lost in translation into wider educational use. As Julian points out, these are 'not' places or physical locations, but that is precisely how I fear the term is already beginning to be used ineducation. So what are the verbs (rather than nouns) that we might use in order to getthe concept across ... or am I worrying unnecessarily? Perhaps I should have more trust in how these ideas and arguments will travel! These are important ideas that stretch well beyond reaffirming the educational potential of libraries and Makerspaces

Cathy - Yes- I share concerns about how the idea of third space gets translated in practice. I worry it gets seen simply in terms of special projects or 'not school' activities; third space becomes an add-on - or enhancement which deflects from more radical re-workings of education and the role of digital media ('you can have a go at third space once you've done your real work'). I think the emphasis on thinking in terms of verbs not nouns is really useful and agree with Neil that it's worth exploring what these might be. l'd like to add though a point about the slipperiness of spaces. I'm interested in how activities/tasks/projects and so on assemble with other stuff as they unfold: with the histories and imaginings of groups and individuals, with established practices for doing school, doing media, doing literacy, doing friendship, teaching, learning and so on, and with other objects and memories lingering in the sites where they happen. What do media literacies become as they assemble with other stuff, and how does this shift as projects move along? For me spaces are always socially produced and as such always fluid and hybrid, and I find it difficult to accommodate the third space metaphor with this view. In my work I'm interested in what gets produced as teachers and children take up rather mundane classroom activities. Often, unsurprisingly in the current climate, this rarely seems 'contested, negotiated and political' in the way you imply, but sometimes I think it really it is. I worry that in working for a third space we may miss some of the ways that children and teachers improvise with the stuff they have to do, overlayering it with other things for example, or finding new pathways through it or ways of being together.

John - Firstly, I agree that language is important here and the way there is a semantic shift as a concept gets worn away by the easy way in which terminology is thrown around, sometimes by well-meaning people, sometimes by commercial interests. I encounter 'affordance' all the time as a substitute for software 'design'. And 'multimodal' is another term which sometimes stands in when people really mean 'multimedia' or just 'media'; it has a different provenance as a study of how meaning is made and comes from social semiotics. Sometimes things sound interesting or new when a term gets used and commercially viable and easily appropriated. There is a company which pairs children in primary schools with maths tutors in the Indian subcontinent for learning concepts they are finding difficult. Soon they will be doing this for literacy lessons. It's not actually a 'third space' as we mean it at all. It's something else. But language is malleable and shifts and belongs in the meaning that is made at the time. Turning to Cathy's point about the difficulty of defining third spaces as something hybrid and fluid and thereby implying that there are spaces which are not, is really interesting. I think the way it's conceived here in our research is to think about the social production of possible spaces. In this way 'third spaces' become more generalised and diffuse expressions of agency, of the qualitatively different possibilities of hybridity and fluidity. So maybe all spaces are as such but some can involve qualitatively different exchanges of cultural capital between the social actors involved.

Julian - Both contributions resonate with other aspects of our project where we talk about 'not school' and various flavours of 'co-creation', in these cases the same risk arises, that we write a book that celebrates marginal activity that involves a small number of volunteers or selected participants, those who probably already possess an abundance of cultural/ academic capital. So we've tried very hard not to do that, by always asking the question - 
does what happens in the third space transform things for a larger number of people back in the second space? Sticking with 'the verbs', a big one for us in the book, and building on John's previous work, is curation / curating as a literacy practice, but how does curation scale and translate, in the ways that Cathy and Neil are thinking about - in other words, does it already get reduced and neutralised in the second space and also can it be agentive in the contested, political sense within but against the grain of that mundane everyday classroom work?

John - Of all the terms in the book the one which is slipperiest and most open to misunderstanding is possibly 'curation' and its associated skill-set, 'curatorship'. The first time I used 'curation' in relation to media and new literacy practices in a conference I was told it might not work because it sounded like a theory of everything and everywhere which would just end up being too diffuse and disappear. And I think this is the big problem with Julian's challenge for it to scale and translate. Because when that happens it runs the risk of losing every kind of nuance in the argument and emerges as a way of simply describing collecting and exhibiting things, an easily made bridge between practices in digital spaces, social media and theory. It runs the risk of becoming observational and celebratory at scale and this wasn't the prime motivation behind trying to use and develop the term. It was a term that grew out of a lot of thinking about social and cultural theory around identity and trying to meld this with what I thought I was seeing in digital media practices around production; aspects of the process which really were different and not adequately accounted for by metaphors around writing, editing or even sharing. A further criticism has been its focus on the individual, though I never intended it to be limited I this way and always saw it as being about one or more social actors engaging in the process, individually or collectively. I think I - and many others - have tried subsequently to refine all of this a little bit, problematise it more and to explain that the word is metaphorical in origin and needs more work! As a term it has resonated with a lot of people in different sectors in education, different spaces but what we need is indeed a way of taking it forward in a more contested sense... Neil and Cathy - what do you think are the possible challenges and opportunities of curation as a term to apply to digital/social media production practices - by groups or individuals?

Neil - 'Curation' is definitely a useful term to keep hold of and work with - it certainly resonates with people when talking about the digital. I have found it less readily co-opted and de-contextualised than some of the other terms that we have discussed. This is perhaps because most people do not readily align themselves with being curators (whereas they feel more comfortable with the idea of being in a 'community' or engaging in 'practice'). It is not a word that is part of the familiar lexicon of education, and as a result tends to pique people's interest. So curation is a useful term as it jolts people out of their comfort zone and makes them think otherwise. This is perhaps because of the obvious pre-digital connotations of the term. I like the sense of deliberation and intent that is conveys. I also like the thoughts that the term provokes regarding the consequences of one's curating practices (i.e. the sense that curation usually involves things being engaged with by others). So we need to keep persisting with 'curation' (even 'though it is yet another ' $C$ ' word). In doing this, there is certainly scope to encourage the widespread use of the term in suitably nuanced ways. The idea of 'co-curation' seems to have taken hold in some quarters, as might wider discussion of what it means to be 'curated' ... making the distinction between one's ability to 'do' curation, as opposed to have curation 'done to' them.

Cathy - I'm not sure I have much to add to Neil's defence of curation, except that I like it too. While I understand the concerns, John, I can also understand why people to use it in celebratory terms - I think celebration is no bad thing sometimes, particularly when teasing out the complexity of practices that are often derided or seen as problematic, although of course we need to be wary of the overly positive accounts that are so common in accounts of digital media projects and practices. I think questions about curation as an ongoing 
process are really useful ones: about how we curate ourselves and others, how we are curated and by who (and maybe what), and what happens with and around what we curate. I also like the way the concept of curation highlights aspects of children and young people's media production that might otherwise go unnoticed. I like the way a focus on this process as one of curation helps us interrogate what's going on here, and foregrounds how personal resonance and experience gets explored and re-negotiated through digital media, things that get written out of dominant educational discourse. Thinking about co-curation - I've heard this term used a little like co-production, when artists, teachers and so on have worked to help produce media artefacts with children and young people. I'm more interested in how the idea of co-curation (if we want to use that term) might help in getting at how third spaces are negotiated, and all the different players - human and non-human that might contribute to this process.

John - I agree that Curation is something that needs to be preserved as a term which is useful, but also complex and nuanced in the context of digital media and learning. I think we try to keep its potential for addressing new literacy practices alive. We have another term which we think might be useful in considering some of these processes and that is the subject of our final question to put to you. We use the term 'Dynamic literacies' in the book to outline a series of literacy theories and practices which are responsive to change of all kinds, societal, semantic, pedagogical. So, it definitely links to both 'third space' and 'curation' and the way our conversation has gone. These kinds of theories are those derived from the New Literacy Studies but are also present in emergent work around sociomateriality and we try to show how these stand in contrast to notions of 'literacy' which are static and autonomous. We also want to connect media literacy theory to pedagogy because we recognise that they are inextricably linked anyway, sometimes even by statute, but almost always by regulatory procedures and by performative assessments of the social actors involved (teachers, children, carers). So, static systems somehow impede the use - or otherwise - of more fluid and dynamic notions of what it is to be literate, to make and share meaning. What we'd like to ask is: How do we conceive of a way of learning which is responsive to much wider definitions of literacy than currently pertain in many countries which have a narrow and even static focus? Or, in other words: How do we design an education system which can work with ideological as opposed to autonomous versions of literacy?

Neil - There are two responses to this kind of challenge. On one hand you can read it as "How do we design a 'better' system?" (which implies suggestions of large-scale reform). On the other hand, you can read it as "How do we support educators to work along these lines in the system that we have?" (which implies suggestions of small-scale tactics of resistance). From the first perspective, the answer I fear probably lies in revisiting (yet again) what it might mean to have forms of curriculum, assessment, pedagogy and expectations of time/place/space that are dynamic. fluid and fully predicated around notions of shared meaning-making. I think that literacy scholars probably know already what these might be ... and they also know why these changes are unlikely to occur as long as the neoliberal project remains dominant. So l'd be tempted to think in terms of the second perspective - i.e. working with what we have. There are plenty of educators already doing what you imply (despite the system in which they work), so there are plenty of examples that we can learn from. Thus it's perhaps useful to position the 'static' forms of literacy that are currently served up in formal education as a something that teachers and students need to critically engage with and critically act against. This is not just a case of critical reflection. Instead teachers need to explore possibilities for critical conduct - these can be indirect (e.g. workto-rule) as well as the occasional critical actions (e.g. direct intervention, subversion, insurrection). Yet these actions need to take place in appropriately pragmatic ways. This sees teachers and students navigating power networks - responding to some impositions in a polite (and perhaps subservient manner), while pursuing other avenues of lively resistance elsewhere. Formal schooling (and therefore formal notions of a static school 'literacy') is not something that is fully rejected or fully acquiesced to. Instead, autonomy and agency in what 
one does with dynamic forms of 'literacy' is an ongoing process of navigation and negotiation.

Cathy - Earlier in this exchange, Julian, you mentioned how you've tried to use the ideas and practices explored in this book to talk back to education more broadly, and specifically I think the school system. It's not surprising that some of the most provocative and inspiring work in media literacy education focuses on not school sites given the ever more hostile policy context in schools. I do get concerned though when the most interesting debate happens mainly outside schools amongst like-minded individuals and groups. So I think we do need to both continually imagine how things might be otherwise in terms of school systems - and try and position ourselves to work for shifts in policy and practice however unlikely these may be - as well as supporting and highlighting 'lively acts of resistance' in schools. There are two points I want to add to Neil's about resistance, based on reflecting on an ongoing project, which involves working with groups of primary teachers to generate collaborative digital media projects that manage to work alongside existing curriculum requirements. One of the striking things about our meetings is the hilarity; the laughter as we talk about ourselves, our practices and thoughts, and the sometimes absurd contexts we find ourselves in. There is something about this that allows us to have better conversations about how digital media might enter classrooms and what this might mean for literacy and for education more broadly, and somehow helps to buoy us all up to try things out. Leading on from this, we've started writing stories about the process of working together, and rather tentatively sharing these with the teachers we're working with.

\section{Triangulation 2: Media Education Summit}

In addition to our virtual conversation with Neil and Cathy, we shared the same three key themes -dynamic literacies, third spaces and curation - with a group of media education and media literacy practitioners at the Media Education Summit in Rome in November 2016. The 'expert focus group' exchange was reaching its final phase so the two discussions were happening at the same time, but we didn't connect the two directly. Discussions during the workshop were recorded, with the informed consent of the participants, and here we offer some transcribed extracts by way of triangulation - between what we had discovered about these key concepts in the major research for the book, what our critical friend scholars said to us in the first phase of triangulation and what these practitioners 'in the patch' shared with us at the workshop.

The workshop participants were media education practitioners, including higher education lecturers, teacher trainers and school or college teachers, but by virtue of their being at the conference and choosing to take part in the particular workshop, all also engaged in research, in some cases working on doctoral projects, at the other end of the scale one of the most prominent figures in media literacy research was in the room. To risk reproducing the 'banalisation' of the term Neil observes above, they are a representative cross-section of the community of practice we hope will read this book. We spent a few minutes rehearsing the key themes from the book, consistent with the interactions with our discussants above, and were joined by two practitioner-researchers, who each shared examples of their own work (Cannon, 2016; Scott, 2016) by way of applications of our three key themes, and then each of the themes was opened up to the group for discussion, with a discussion prompt in each case. Each of the three framings is here followed by extracts from the discussion.

Should we recognise the skills, knowledge and dispositions which go with curation as a practice and build on them in education? How can we do this? What conditions are necessary for this to succeed?

\section{$\underline{\text { Participants }}$}


It reminds me of library science and classifications, people taking a three decimal system over to tagging, in Texas we call it 'tag wrangling', managing the tags. It's a form of curation in that you're naming things but also giving them priorities, these intertexts, and giving value to these objects. And taste and value definitely come into it.

I'm interested in the things that have been purely facilitated by curation. Like being a geocacher, it is a digital treasure hunt. So you go out and find boxes, using your phone with GPS to do that. Some people would have no interest in that if it were not for the digital technology, so it's a properly outdoor activity that is only really made possible by the interaction with an app on a phone, which is slightly different to storifying photos or curating videos, but it's a curation, with sharing online, but it's more the case with this that the technology makes the activity itself possible (rather than just using the tech to curate).

Clearly the technology is part and parcel, but as you were talking the things that came to mind were the curation that takes place in performance, the 'shelf' of performance, going back to the Goffmanesque performance of self. So I am hearing curation as curation / the performance of curation and I don't think you can separate those, even if you are curating for an audience of one but also it's a performance to self as well as of self. We may have been privileging the technology too much, there is a caution there, it's about whether it's explicity digital curation.

But with social media, the fact that young people are routinely counselled by careers advisors to refine their curation of self, to expunge it, to redo it with respect to the audience, it's not something anyone ever said to them about the shelf in their bedroom.

John - This thing of the digital making hidden processes visible, so with this in mind, do we need more by the way of theory than Goffman (see 1990), who was writing about industry, and particularly the advertising industry and how people present themselves at work and then go back home to be. Whereas social media, if we're saying at least a version of it is now synonymous with curation, raises the question of what other things are important apart from this front and back stage, what other theories do we need?

Dynamic literacies - How might literacy events which take place on and off screen, between social actors and artefacts in a range of locations become part of the pedagogical frame?

\section{Participants}

It's the question of how are we going to use these new 24/7 experiences and competences in education, it's not by chance that we are all working on this idea, and I think the answers are in understanding how the structures we already have can respond to these new points of experiences in the digital world.

But this is the history of literacy and it's NOT different, it's not about the devices and it's not about the texts. It's about the institutional control of the definition of literacy which equals power. And that's what we miss, because we keep focusing on the steps to literacy and how we do the pedagogy for this device or that device. Languages are dialects with an army. It's about power. So how can we give social capital to our students, and how can we make the classroom a place where media education can maybe unlock those handcuffs?

John - in our research we make an argument which traces the story of literacy in that way, from its origin, in a step by step way to gain knowledge of the letters, in order to be able to read, to perform, to be economically successful and we end up with a political and ideological position which is there is no media literacy as such, there is (just) literacy and it's dynamic, and the media artefacts, texts and practices are part of what we all do every day. 
Participant - I think between us we've thrown around ideas that we use literacies as something to 'bandwagon off of', particularly in the UK. But we get confused and distracted by talking about digital, I get the spirit of where you are heading, but it feels a bit like going around in circles, literacy confers status on everything that comes before it (eg media, digital), so is it just the same with dynamic?

Julian - there's a clear political position in our research which is that the institutional power dynamics at work render most people, if not illiterate, then outside of literacy in one way or another. It's an old idea that the schooled version of literacy alienates more people than it includes, but the book doesn't just say that and leave it, in every chapter we try to work through case study examples and examples of research which do seem to be shape-shifting what counts as literacy, who gets to speak, what counts as knowledge.

Question: When digital media is used to create a third space with the effect of transgressing disciplines and traditional ideas about knowledge and expertise, can educational practices 'shape-shift' to challenge epistemological power relations?

\section{$\underline{\text { Participants }}$}

The thing I worry about here is the fact that there are influential people in our own community who are instrumental, narrowing down particular types of knowledge that will benefit you and there are academics in our field presenting that view of literacy and I worry that there has to be route to take those people on in some way.

It's not a functional model, it's dysfunctional. We should write a book about the failure of literacy. If this is political, for example play - it's not just that play is purposely excluded, it is, because it doesn't fit the systemic, institutional version of education. But if it's political, there are a couple of ways, one way is to go' full tilt, bandwagon' and the other is incrementalism. Building a solid base, step by step, if you have a strategy. I would go incremental and find the opportunities, be successful, disseminate it, find new ways to work.

John - it's the problem of the institutional model of literacy being chronically unambitious for 2016, and then being on the front foot. Making incremental progress. This is an increment, this room.

\section{$\underline{\text { Participants }}$}

The front foot can just be 'fuck neoliberalism' (referring to Springer, 2016). Calling it when we see it. Not worrying about upsetting the people we don't want to upset.

It seems to me that actually unless you still want to be in the game of let's educate the workers so we can move them from the school gate to the factory gate, you have to add emotional literacy, the question of what's the point and why do we care?

\section{Implications}

In taking forward our three key findings from our larger project into these two triangulation activities, we can see how the expert group and the teacher-practitioners articulate, within and out from our discursive framework, the two inter-connecting strands of literacy in the digital age, the text and the affect, aesthetic engagements and judgements, but also how these are two sides of the same coin, (media) literacy and pedagogy in this push and pull. How we define our literacy in a society is how we define your pedagogy, bounded by either focussing only on texts and the design of social futures or how we talk about social futures in 
terms of affects and socio-materiality, the artefacts and the bodies and the devices in the classroom, at home, in the community and in between, in the third space. The objectives of this special issue are ambitious - to offer new knowledge about digital media for teaching and learning in school, connecting teaching and learning in and out of school and, from this, the use of digital media in meeting societal challenges. Our research, informing this 'article as discussant', posits a new way of thinking about literacy (as dynamic), a new way of thinking about educational space and a new way of thinking about curation as an agentive learning practice. We offer these as pre-requisites for participation and social transformation.

The two sets of triangulation in this article were previously published as an afterword chapter of Potter, J and McDougall, J (2017) Digital Media, Culture and Education: Theorising Third Space Literacies. London: Palgrave MacMillan. Permission to republish has been granted by the publisher and participants.

\section{References}

Berger, R and McDougall, J, 2011. 'Apologies for Cross-Posting: a keynote exchange' in The Media Education Research Journal 2(1)

Bhabha, H. 1994. The Location of Culture, London, Routledge.

Burnett, C., Davies, J., Merchant, G. \& Rowsell, J. (eds.) 2014. New Literacies around the globe, London: Routledge.

Cannon, M. 2016. Media-making matters: exploring literacy with young learners as media crafting, critique and artistry. PhD, Bournemouth University.

Goffman, E. 1990. The presentation of self in everyday life (New edition), London, Penguin.

Gutierrez, K. 2008. Developing a sociocultural literacy in the third space. Reading research quarterly, 43, 148-164.

Scott, F. L. 'Young children's digital literacy practices at home: social, physical and classed', pp. 173-184 in Pereira, I., Ramos, A. and Marsh (Eds) (2016). The Digital Literacy and Multimodal Practices of Young Children: Engaging with Emergent Research. Proceedings of the first Training School of COST Action IS1410, University of Minho, Braga, Portugal, 6th - 8th June, 2016. Braga: Centro de Investigação em Educação (CIEd) [Accessed Nov 2016: http://digilitey.eu]

Selwyn, N. 2014 Is Technology Good for Education? London: Wiley.

Springer, S (2016). 'Fuck Neoliberalism'. An International Journal for Critical Geographies, 2016, 15(2): 285-292 